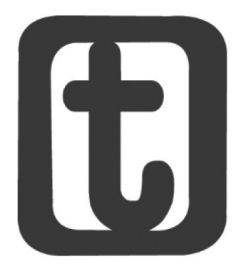

\title{
MULHERES DA PAZ: VIVENDO O COTIDIANO EM CONFLITO
}

\author{
Women of peace: the daily living in conflict \\ Fabiana dos Santos Rocha' \\ Márcia Santana Tavares ${ }^{2}$
}

\begin{abstract}
RESUMO
Neste artigo, debruçamo-nos sobre o cotidiano de sete mulheres residentes no bairro de São Cristóvão, localizado na cidade de Salvador-BA, que passaram pela formação do Projeto Mulheres da Paz (MP), do Programa Nacional de Segurança Pública com Cidadania (PRONASCI - Ministério da Justiça), com o intuito de refletir sobre mudanças e permanências em suas vidas a partir da sua participação no referido projeto. Embora a participação no projeto tenha contribuído para o fortalecimento de sua autoestima, acesso a conhecimento e descoberta de sua capacidade de liderança, o projeto reforça os papeis de gênero tradicionais, o que comprometeu o processo de empoderamento e expôs as mulheres a situações de risco e vulnerabilidade no trabalho de mediação de conflitos.
\end{abstract}

\section{PALAVRAS-CHAVE}

Mulheres da Paz. Violência. Gênero. Empoderamento.

\section{ABSTRACT}

In this article, we focused on the daily lives of seven women residing in the neighborhood of São Cistóvão, in the city of Salvador, Bahia, who whent

1 Cientista Social. Mestre em Estudos Interdisciplinares sobre Mulheres, Gênero e Feminismo. Cientista Social na empresa HOLLUS Serviços Técnicos Especializados LTDA (HOLLUS, Dias D’Ávila, Brasil). Av. Lauro de Freitas, n 1302, Centro, Dias D’ávila, BA, CEP.: 42850-000. E-mail: <faredalu@yahoo.com.br>.

${ }^{2}$ Assistente Social. Doutora em Ciências Sociais. Professora Adjunto II do Curso de Serviço Social e Professora e Coordenadora do Programa de Pós-Graduação em Estudos Interdisciplinares sobre Mulheres, Gênero e Feminismo da Universidade Federal da Bahia (PPGNEIM/UFBA, Salvador, Brasil). R. Prof. Aristídes Novis, nº 197, Federação, Salvador, BA, CEP.: 40210-909. E-mail: <marciatavares1@gmail.com>. 
through the training of the Project Women for Peace, promoted by the National Public Security and Citizenship (PRONASCI - Ministry of Justice), in order to reflect on changes and continuities in their lives from their participacion on this project. While participacion in the project has contributed to strengthening in self-esteeem, access to knowledge and discovery of leadership, the project reinforces tradicional gender roles, which undertook the pocess of empowering women and exposed then two risky situations and vulnerability while in the work of conflicts mediations.

\section{KEYWORDS}

Women of Peace. Violence. Gender. Empowerment.

Submetido em: 17/9/2014

Aceito em: 20/5/2017

\section{INTRODUÇÃO}

Este artigo traz uma versão resumida da dissertação de Mestrado intitulada “'Botou foi a gente no fogo! Queria ver a gente se queimar!': Um estudo sobre as Mulheres da Paz de São Cristóvão, Salvador (BA)", cuja pesquisa empírica foi desenvolvida entre novembro de 2012 e junho de 2013, período em que acompanhamos e entrevistamos nove mulheres do bairro de São Cristóvão, com a finalidade de investigar sobre como estas mulheres significam e traduzem a sua formação como Mulheres da Paz, procurando refletir acerca das reais condições para o desempenho da função de mediadoras de conflitos, diante do direcionamento dado pelo Programa Nacional de Segurança Pública com Cidadania (PRONASCI), que as classificou como em estado de vulnerabilidade social ${ }^{3}$.

O PRONASCI foi lançado em 2007, pelo Ministério da Justiça com um caráter principalmente preventivo. A partir do novo programa federal, esperava-se provocar mudanças nas ações policiais, pautadas nos princípios da legalidade e da equidade, com a inserção da comunidade em alguns planos de ação. A política do PRONASCI aparece como uma proposta de intervenção tida como inovadora por agregar o conceito de prevenção ao combate ao crime e, deslocar sua atenção para os sistemas informais de controle da criminalidade - a saber, família/mulheres e comunidade. Entre

\footnotetext{
3 Vulnerabilidade e violência são conceitos que permeiam os debates sobre exclusão social na América Latina. Nesse caso, a vulnerabilidade é associada à exposição ao risco e, consequentemente, à capacidade de resposta, material e simbólica, que os indivíduos, famílias e comunidades conseguem dar frente às situações consideradas de risco (BRONZO, 2009).
} 
os principais eixos do PRONASCI se sobressaem os seguintes: a valorização dos profissionais da segurança pública que, por meio do Projeto Bolsa-Formação, recebem uma remuneração adicional e mensal de $\mathrm{R} \$$ 400, condicionada à participação em cursos de formação ou de educação continuada, habilitados pelo Ministério da Justiça; a reestruturação do sistema penitenciário, mediante a criação de vagas e investimento em equipamentos de segurança, bem como prestação de assistência jurídica a presos (as) e familiares, de forma integral, pela defensoria pública; o combate à corrupção policial através da instalação de laboratórios contra a lavagem de dinheiro, de Ouvidorias e Corregedorias de Polícia, além do envolvimento da comunidade na prevenção da violência (BRASIL, 2010).

O eixo do PRONASCI que envolve a comunidade, as famílias e as mulheres é o Projeto Mulheres da Paz. A partir do Mulheres da Paz seriam formadas líderes comunitárias, residentes em territórios que foram classificados pela equipe do governo como vulneráveis e violentos, para construção e fortalecimento de redes sociais de prevenção e enfrentamento à violência, mediante administração autônoma por parte dos estados e municípios. As beneficiárias foram escolhidas por meio de processos seletivos públicos realizados por gestores locais (municípios ou estados).

A prioridade do PRONASCI eram os jovens considerados em condições de "[...] vulnerabilidade familiar e social" (BRASIL, 2007; 2008). O lugar das mulheres, também consideradas nas mesmas condições dos jovens, ficou representado pela função de cuidadoras desses jovens, contrariando investiduras de mulheres e feministas para o enfrentamento à violência de gênero4.

Neste sentido, o Estado revalida os papeis tradicionais de gênero, a "vocação natural" da mulher para "cuidar"', "bem servir" e, aloca

${ }^{4}$ O conceito de ‘violência de gênero’ se refere à violência produzida no espaço
das relações sociais, cuja ênfase é dada ao seu caráter relacional num contexto
de desigualdades de gênero. Essas relações, de forma complexa e contraditória,
abrem possibilidades às práticas sociais, inclusive de lutas individuais e coletivas
em que os indivíduos envolvidos recriam suas vidas, reafirmando ou rompendo
com as desigualdades (ALMEIDA, 2007).
5 O caráter relacional do gênero trama identidades e subjetividades sexuadas,
enquanto as relações de gênero plasmam papéis, atributos e hierarquias de
gênero que se re - definem nas práticas da vida cotidiana (DELGADO; TAVARES, 
as mulheres pobres como suas substitutas na provisão de bens e serviços sociais básicos (PEREIRA, 2010), dando continuidade aos critérios evidenciados no Plano Nacional de Políticas para as Mulheres (PNPM). Tais critérios envolvem, fundamentalmente, o enfrentamento à violência como prevenção, combate, assistência e garantia de direitos em setores como da saúde, educação, assistência social e justiça, com ações articuladas. A capacitação das lideranças comunitárias nas temáticas da violência de gênero constituiu algumas das ações com as quais se pretendia combater desigualdades e discriminações de gênero (ROCHA, 2013).

A especificidade no planejamento de políticas sociais já constitui uma prática nos programas de transferência de renda. Na análise de Gomes e Sorj (2011), envolve discursos e práticas díspares entre si, por um lado, na mobilização de "[...] noções e pressuาpostos maternalistas, associados à feminilidade [...]” (GOMES; SORJ, 2011, p. 148); por outro lado, na reunião de novas abordagens sobre cidadania baseadas na individualização dos sujeitos, mediante o enaltecimento da autonomia e do auto desenvolvimento, conforme a ideia de empoderamento ${ }^{6}$ especificada no referido projeto.

Ao serem elevadas à função de 'provedoras de bem-estar', as mulheres assumiram uma posição de desvantagem por conta de seus parcos recursos para a almejada provisão. Isto porque, no lugar de políticas públicas de gênero - proposta feminista que indica transformações nas condições de vida das mulheres e da população de modo geral - o governo adota políticas voltadas para as mulheres dentro dos padrões tradicionais atribuídos ao universo 'feminino', logo, políticas reprodutoras de desigualdades de gênero. Há, portanto, um reforço do lugar de cuidadora/beneficiária para as mulheres no campo da assistência social (GAMA, 2008).

2012). Os papéis sociais tradicionais designados para homens e mulheres seguem uma clara demarcação. Enquanto os homens têm 'cuidado com' seu desempenho no trabalho e o sustento do grupo familiar, as mulheres 'cuidam de' seus familiares e das pessoas com as quais convivem, esquecendo-se de si mesmas na dedicação aos outros (TRONTO, 1997).

6 A expressão empoderamento é uma tradução livre do termo inglês empowerment. Consiste em um processo social, cultural, psicológico ou político mediante o qual indivíduos e grupos sociais se tornam capazes de manifestar suas necessidades, revelar suas preocupações, descobrir estratégias de envolvimento na tomada de decisões e atuar no âmbito político, social e cultural tendo em vista a satisfação de suas necessidades. 
A concepção de gênero do Estado esboça também uma das formas de desigualdade inseridas nas relações de poder dentro das instituições estatais no Brasil (ALVAREZ, 1988). Com relação à noção de empoderamento, o Estado lança projetos reprodutores dessas desigualdades estabelecidas no interior do espaço político-partidário, com concessões aos grupos sociais discriminados; espelha a relação conflituosa entre a subordinação da mulher na sociedade e o poder político institucionalizado. Assim, distancia-se da perspectiva feminista que concebe empoderamento como escolhas ou autodeterminações, ou ainda, o poder de fazermos escolhas estratégicas, de forma que administremos nossas vidas na gama das relações e da expansão de limites sociais.

O destaque do projeto MP direcionado à agênıcia humana ou ao protagonismo social conectou as mulheres entre os níveis micro e macrossociais, tornando a atividade de capacitação o ápice do projeto. A mulher passaria a se reconhecer como participante ativa dos processos sociais, como protagonista da sua história. Nesse sentido, configura-se o deslocamento do nível do empoderamento individual para o empoderamento via comunidade, no qual elas desempenham o papel de cuindadoras dos jovens em situação de violência (GOMES; SORJ, 2011) - como ocorreu com as mulheres residentes em São Cristóvão, bairro localizado na periferia de Salvador (BA) - conforme discutiremos nas próximas linhas.

\section{TRAÇADOS URBANOS: PARA CARTOGRAFAR SÃO CRISTÓVÃO E SUAS MORADORAS}

A amostra da pesquisa foi composta por nove mulheres, sendo sete Mulheres da Paz e duas coordenadoras que compuseram as equipes de trabalho. Os critérios seguidos para a escolha entre as MPs foram dois: em primeiro lugar, aquelas que já exerciam liderança comunitária antes da formação, somadas às que não haviam passado pela experiência, porém verbalizavam descontentamento com o projeto do PRONASCI nas oficinas; em segundo, foram agregadas outras MPs, indicadas tanto pelo primeiro grupo constituído como por uma das coordenadoras. Todas as MPs eram moradoras do bairro São Cristóvão, com exceção de uma moradora 
de outra cidade, mas que atuara no mesmo bairro. As suas idades variavam entre 33 e 63 anos.

Para as entrevistas, seguimos roteiros previamente estabelecidos, específicos para as Mulheres da Paz e para as duas coordenadoras do projeto. A pesquisa se desenvolveu em torno do conhecimento situado e corporificado, assumindo as perspectivas dos grupos excluídos como dotados de posicionamento político (HARAWAY, 1995).

Para desvendar o contexto em que viviam as mulheres investigadas, foi preciso situá-las no traçado urbano de Salvador, onde a população se encontra polarizada entre bairros populares e de elite, ou seja, há uma divisão centro-periferia, com a pobreza localizada, basicamente, em seu entorno, distribuída em conjuntos habitacionais, loteamentos e terrenos ocupados irregularmente, que refletem a distribuição desigual de bens e serviços públicos fundamentais à sua reprodução, a exemplo de infraestrutura, transportes, saúde, educação e segurança entre outros (BORGES; CARVALHO, 2012).

No que toca à questão da segurança pública, o PRONASCI reuniu, entre as ações locais, o projeto 'Território de Paz', uma política que objetivava a pacificação de territórios do ponto de vista da segurança pública e das condições de convívio social nos espaços considerados violentos. Na Bahia, o 'Território de Paz' foi lançado em Salvador, no bairro Cabula e em Camaçari, cidade localizada na Região Metropolitana. Na capital baiana, o Projeto Mulheres da Paz manteve o 'Território de Paz' do Cabula, especificamente, o Beiru/Tancredo Neves, acrescentando o bairro de São Cristóvão, devido aos altos índices de violência e à articulação entre uma das lideranças comunitárias e gestores públicos (ROCHA, 2013).

O bairro de São Cristóvão surgiu em 1940, devido ao loteamento da fazenda da família Cachoeira e à construção do Aeroporto de Salvador (SANTOS et al., 2010). Contudo, tanto o bairro como o comércio se desenvolveram a partir da década de 1980, ao mesmo tempo em que cresceram também os problemas. 0 racismo, por exemplo, impediu a absorção de pessoas negras em trabalhos qualificados. Conforme recorda Zeferina (63 anos e líder comunitária), 
[...] eles só gostavam de dar emprego a meninas loiras, dos cabelos compridos, bonitas. [...] Lá, as meninas entravam sem fazer teste sem nada. Eu tive que fazer tudo! [...] porque aqui há uma coisa que eles não botam muito pessoas de cor.' [...] Sabem o que foi que me botaram? Servir cafezinho... (MP Zeferina, 17/06/2013).

No Brasil, o racismo parece condicionado à cor da pele, entretanto, possui uma justificação cultural, cujo objeto é a forma de existir dos negros. Negros são subjugados e desumanizados segundo métodos multifacetados (FANON, 1980) - na capital Salvador, àquela época, pela exclusão de negros no setor de atendimento ao público. Zeferina completa:

As meninas tudo lindas e maravilhosas, cabelos batendo nos quadris, com aqueles gorrinhos brancos, lindas maqueadas, eu só pretinha, com meu cabelo só alisadinho, mas não fazia vergonha pra ninguém. [...]

Zeferina se revela como indivíduo ‘aculturado' e 'desculturado' que, oprimido, esbarra no racismo. São-lhe negados os meios de existir e, consequentemente, culpabiliza-se (FANON, 1980). Mediante as formas de opressão, a população racializada utiliza mecanismos de defesa reveladores do seu estado de 'mumificação cultural'. Neste estado, os grupos sociais inferiorizados procuram imitar os valores dominantes e, assim, desracializam-se, partilhando convicções, doutrinas e preconceitos.

Em virtude de suas crenças serem deslegitimadas, esmorecem suas identidades 'originais', o que para Fanon (1980) torna sinônimos alienação e assimilação. Aderem incondicionalmente aos valores e à cultura que os inferiorizam. Portanto, culpabilidade e inferioridade introjetadas desencadeiam um processo de normalização do racismo. A cultura o modela, repercutindo-o em todos os níveis de sociabilidade.

A transferência da população pobre para as regiões periféricas fomentou as diferenças que se firmavam na capital e, a falta de investimento em equipamentos públicos, ao longo dos anos, criou um ambiente de formação de lideranças, conforme interesses diversificados, coletivos ou individualizados (SCHUTTE; JOSÉ, 2008), que abordaremos no próximo tópico. 


\section{A FORMAÇÃO DE LIDERANÇAS LOCAIS: MULHERES DA PAZ EM CONFLITO}

Formaram-se grupos diversificados no bairro em desenvolvimento, tais como religiosos (evangélicos, católicos, candomblecistas, entre outros) artísticos, esportivos, alguns conflitantes entre si. Porém, diante da atuação das Mulheres da Paz como lideranças comunitárias e das queixas recorrentes sobre a violência no bairro, daremos ênfase à formação das lideranças comunitárias - ou de bairro - e do tráfico. Enquanto os últimos recorrem à violência na disputa de territórios e de prestígio, os primeiros se reúnem em busca de melhorias para o bairro, através de estratégias para angariar recursos e se inserirem nas relações sociais (ZALUAR, 1985).

O conflito se destina a resolver dualidades divergentes, “[...] é um modo de conseguir algum tipo de unidade, ainda que através da aniquilação de uma das partes conflitantes" (SIMMEL, 1983, p.122). Levamos em consideração que os aspectos positivos e negativos são integrados e estão constituídos como categorias de interação que dão forma à sociedade. Quando evidenciamos as lideranças de bairro, de modo geral, destacamos sua condução dos conflitos e reivindicações dos grupos de modo a favorecer o exercício da cidadania ativa entre seus pares.

Conforme Borges e Pinheiro (2012), o desenvolvimento de uma localidade está diretamente ligado a essa mobilização comunitária em prol de melhorias nas condições de vida dos (as) moradores (as). Em torno dessas atividades, as mulheres pobres desempenham forte atuação política, limitadas aos seus bairros de moradia. Criam grupos sociais e instituições ou se aliam aos mesmos (BONETTI, 2003).

De acordo com Caldeira (1987), a mobilização social das mulheres antecede a sua condição de gênero e o papel que lhes é designado enquanto mães; envolve a luta pela defesa de interesses próprios, para além dos interesses de cunho maternal. Simmel (1983) já afirmava que a oposição pode ser tanto um elemento da relação como uma função que a constitui. Neste debate, os elementos de oposição são as motivações diversificadas do grupo para a luta: lançam mão da identidade de mãe nos processos de negociação de interesses próprios do seu grupo, ou ainda interesses particulares, junto a entidades, instituições públicas, ou até mesmo para 
barganharem a permissão do cônjuge para a saída do lar. No bairro de São Cristóvão, os grupos comunitários se firmaram obedecendo a esse perfil.

Os padrões observados na atividade de liderança comunitária em bairros pobres serviram de base para a formulação do Projeto Mulheres da Paz (ROCHA, 2013), com o intuito de promover uma mudança naquela realidade hostilizada pela criminalidade violenta. Para atender a demandas desses grupos, o Projeto Mulheres da Paz, contemplou a questão de gênero e envolveu uma noção de empoderamento das mulheres que se restringiu à constituição da autoestima do self feminino e à valorização de sua atuação junto à comunidade (GOMES; SORJ, 2011).

Com relação aos grupos de liderança do tráfico de drogas, os códigos de conduta são demarcados por imposições pela força sobre os outros, instaurando a violência. Os conflitos (no universo do crime) extinguem todos os outros elementos de sociação ao considerarmos que o fator socializante surge no limite declarado à violência (SIMMEL, 1983). O processo de associação de grupos envolvidos com a criminalidade violenta pelo tráfico de drogas se manifesta de forma sistemática; associam-se ou rivalizam-se com grupos de outras localidades, com propósitos de manutenção e expansão de seus mercados ilegais, bem como de aumento de prestígio social (BEATO; ZILLI, 2012).

Em São Cristóvão, com o passar do tempo, aumentaram as rixas entre invasões. Os embates desencadearam, em 2006, na invasão da escola Municipal de São Cristóvão por um grupo de jovens envolvidos com o tráfico da região; além disso, decorreu na proibição pelos traficantes de prestação de atendimento, pelos técnicos do Centro de Referência de Ação Social (CRAS), aos residentes de ruas com lideranças rivais (BAIRROS..., 2006).

A atuação das lideranças comunitárias/MPs revela um momento no qual o estágio de violência declarada se sobrepõe a outros relacionamentos, ratificando um elemento comum introduzido na hostilidade. Cada rua ou pequeno bairro de São Cristóvão tem uma associação. Todas se comunicam e se unem por interesses comuns, estabelecendo um bom relacionamento entre si, esboçando expressiva atuação política. Moradores (as) conseguiram algumas 
melhorias, embora não tenham sido suficientes para promover bem estar e segurança para aquela população.

As relações de conflito, somadas a forças unificadoras promovem grupos como unidade viva e concreta. As lideranças de bairro recorrem aos gestores em busca de medidas emergenciais e assistenciais para a oferta de serviços públicos básicos (MILANI, 2006). Entretanto, não alteram as condições de pobreza, asfixia e mumificação cultural. Em São Cristóvão é forte a atuação das lideranças comunitárias, embora esse associativismo seja pouco expressivo quando nos referimos à sua interferência quanto à formulação de políticas públicas (AVRITZER, 2007). Nesses parâmetros, a inserção popular nas resoluções públicas permanece frágil, sem poder de reivindicação.

A população enfrenta problemas decorrentes de outros conflitos que serão expostos e analisados adiante. Especificamente, as mulheres, improvisam formas para lidar com a escassez de recursos: fazem bicos como faxineiras, catadoras de material reciclável, artesãs, vendedoras de cosméticos ou salgados. Lançam mão de aspectos de solidariedade entre determinados grupos e se caracterizam como agentes do setor informal. Ao mesmo tempo, engendram estratégias para lidar com os diferentes conflitos existentes no bairro, que discutiremos no próximo tópico.

\section{Recortes de conflitos no bairro}

Foi possível compreendermos o temor e desconforto entre as participantes de turmas de São Cristóvão em abordar as ações dos envolvidos com a atividade do tráfico de drogas e a consequente represália policial. Uma das razões foi a presença de crianças na escola-sede do curso, que poderiam ter algum vínculo com envolvidos (as) na atividade do tráfico e delatá-las como $X 9^{7}$.

A impossibilidade de um relacionamento seguro entre a população negra pobre e a instituição policial, bem como as agressões e mortes sofridas pelo grupo denotam faces do racismo institucional. Não é à toa, portanto, que as MPs de São

\footnotetext{
${ }_{7}$ A falta de entendimento sobre a atuação das Mulheres da Paz no bairro foi atribuída à repercussão da divulgação do projeto no bairro pela equipe de comunicação na Bahia (ROCHA, 2013).
} 
Cristóvão sintam aversão aos agentes de segurança, conforme revelam Thaís e Diana:

A força policial gera violência, impondo o poder, ao algemar, bater, sequestrar adolescentes de 11, 12 anos, envolvidos, ou não, no tráfico. A violência no bairro é uma represália à ação policial. (MP Thaís, 30/11/2012).

A violência policial se estabeleceu como norma institucional no decorrer da sua história política. Constitui-se como um elemento do universo do crime (CALDEIRA, 2000). Cotidiana e protegida por lei, a violência da PM controla a população, tratando desigualmente elites e pobres, negros e brancos. Dessa forma, o instinto de hostilidade inibe o estabelecimento de laços de sociabilidade e a população pobre e negra se torna o alvo do tratamento violento em sua forma explícita (SILVA, 2008).

Todavia, as mulheres são afetadas por esses conflitos de forma particular, em virtude da sua condição de gênero, isto é, sua responsabilidade pelo cuidado com familiares e filhos. Conforme esclarece Thaís:

Outros conflitos são gerados pela violência: a baixa escolaridade das mulheres, que acabam indo trabalhar em casa de família; desemprego; mulheres, todas as mães, deixam de trabalhar e procurar trabalho longe do bairro para acompanharem seus filhos. Como é que trabalha assim? Quem vai deixar seus filhos nessas condições? (MP Thaís, 30/11/2012).

Assim, veem-se impedidas de buscar crescimento intelectual e emprego, por temerem a possibilidade manifesta de que seus filhos (as), desacompanhados (as), sejam violentados. A iminência de agressões em casa ou nas ruas, de aliciamento para o tráfico e consumo de drogas, bem como assassinatos regula o comportamento e estabelece limites de atuação das moradoras que são mães.

O segundo maior conflito evidenciado, embora atrelado aos desmembramentos do tráfico de drogas, foi briga entre vizinhos. Várias razões são apontadas: disputas por pedaços de terra, aparelhos de som no volume alto, brigas entre mulheres por ciúmes de namorados ou maridos, lixos jogados às portas das 
casas, etc. Questões que frequentemente sofrem interferência dos traficantes, mesmo de forma indireta. Quando uma das partes do conflito tem qualquer tipo de envolvimento com os 'meninos' do tráfico, a outra parte interrompe a disputa, por temer represálias, como conta a MP Marta: - Eu nem posso reclamar porque essa vizinha é assim com os meninos. Eu! Deixo prá lá.

O indivíduo que tem a sua honra abalada, decorrente de um conflito com um vizinho, em determinados momentos a retoma, lançando mão da 'porrada' para reverter a situação de rebaixamento (MACHADO; NORONHA, 2002). Embora os (as) moradores (as) de São Cristóvão, por vezes, empreguem a força física e agressões verbais para revidarem ofensas recebidas, recorrem também a artifícios como intriga, desgaste pessoal, xingamentos e perseguição para lidarem com as desavenças.

O padrão de urbanização da cidade de Salvador compromete a efetividade do controle, ordenamento do uso e ocupação do solo. A precariedade da prestação de serviços públicos aos (às) cidadãos (ãs) pobres da capital (FERNANDES; REGINA, 2005; PEREIRA, 2008) desperta na população indignação, fúria e violência. A população assume a maior responsabilidade pelo enfrentamento direto das questões de conflitos, em alguns casos, respaldada pelo uso da violência. Assim, vimos como a violência cotidiana gera conflitos entre moradoras (es) no bairro de São Cristóvão. No próximo tópico, apresentaremos as formas de enfrentamento às condições de pobreza e violência desta população; bem como quais as suas estratégias para manterem um distanciamento das situações de conflitos.

\section{As estratégias de mediação dos conflitos}

Na perspectiva feminista, as autodeterminações são concebidas como processos nos quais mulheres administram as suas vidas para o desenvolvimento intelectual, emotivo e profissional. $\mathrm{O}$ enfrentamento das situações de conflitos no decorrer da vida cotidiana, envolvem as (pré) condições de recursos para as escolhas e ações dentro das possibilidades postas (SARDENBERG, 2006).

Neste sentido, a Política Nacional de Enfrentamento à Violência contra as Mulheres defende que o empoderamento das mulheres não pode prescindir do enfrentamento da violência mediante 
prevenção, combate, assistência e garantia de direitos, o que implica na articulação de diferentes políticas públicas, tais como saúde, educação, assistência social, segurança pública, cultura e justiça entre outras.

Com relação à operacionalização da política de segurança do PRONASCl, destacamos a maneira como o Estado cooptou mulheres pobres para acolherem jovens (pobres), classificados como em situação de risco social e exposição à violência. Isto é, elas passaram por um processo formativo (Projeto Mulheres da Paz) para encaminhá-los aos serviços públicos de assistência social. Contudo, esta forma de envolver as mulheres no combate à criminalidade fez recair sobre si a violência de gênero, perpetrada pelo Estado.

A violência materializa-se pela omissão e pela sobrecarga de trabalho, justificada na essencialização do sujeito feminino. Neste aspecto, assemelha-se com o Programa Bolsa-Família (MARIANO; CARLOTO, 2009). O Estado, ao se apropriar da condição de mulher tradicionalmente concebida como cuidadora, onerou suas tarefas diárias, sem oportunizar transformações reais na sua vida; como também negligenciou a sua condição de pobreza e violência, pois, ao não inserir as mulheres beneficiárias num programa de assistência em rede, elas ficaram mais expostas a situações de conflito (ROCHA, 2013).

As mulheres beneficiárias da política do PRONASCI, em Salvador, não contaram com recursos para a atividade de encaminhamento. Indagadas sobre as suas estratégias de enfrentamento frente às situações de conflito relatadas, desabafam:

[...] Tive infecção intestinal e fui ao hospital, [...] mas eu fugi, preocupada com meus filhos. [...] As mulheres também protestam junto aos policiais e eles as inibem. [...] No geral, se calam. [...] Tem que pedir permissão para passar pelos locais, senão morre de forma muito violenta, eles (os traficantes) tiram a cabeça. Uma MP levou tesouradas de duas traficantes (MP Thaís, 30/11/2012).

A gente não enfrenta, né, a gente tem que conviver, né, [...] Muitas se prendem dentro de casa, outras tem que trabalhar, tem que se arriscar mesmo, [...] e ir em frente. (MP Lourdes, 07/03/2013).

Faço de conta que não vejo, para viver. [...] Uma 
moça que tava fazendo um curso de segurança, [...] aí os meninos invadiram a casa dela estupraram e espancaram ela e a mãe, atrás da arma dela, mas não tinha [...], nem deixaram ninguém chamar a SAMU, disseram que ela só ia sair para o hospital no carrinho de mão pra todo mundo ver. (MP Marta, 07/12/2012).

A associação de mulheres ao tráfico de drogas revela o estado de asfixia social (CARNEIRO, 2011) em que vivem as moradoras da região. Há grupos de mulheres que passam a desenvolver atividades ligadas ao tráfico, assim configurando o principal motivo do seu aprisionamento (SOUZA, 2009). Geralmente, essas mulheres iniciam ou assumem temporariamente as atividades criminosas quando cônjuges, namorados ou irmãos estão presos. As detenções de mulheres por criminalidade violenta são poucas (DOURADO, 2013), na maioria dos casos levam drogas para os maridos presos, e, por isso, não representam perigo para a sociedade (DETTMAR; SILVEIRA, 2013).

Em São Cristóvão, foi possível observar mais um elemento referente ao envolvimento de mulheres com o tráfico de drogas. Desta vez, a reprodução dos padrões violentos dos traficantes de drogas da região. De acordo com alguns relatos, havia mulheres que lideravam ações criminosas, participavam de linchamentos e agressões físicas. A forma encontrada pelas demais mulheres do bairro para se manterem vivas e longe de agressões é ficando em silêncio e reclusas em suas casas. As MPs afirmam que reivindicam até certo ponto e, depois, silenciam diante da impotência em relação aos poderes públicos e dos envolvidos.

Há mulheres que enfrentam o medo e, trabalham fora de casa e do bairro para sustentar a família. Arriscar-se é um termo que transparece esses sentimentos frente à violência e à necessidade de seguirem em frente. Algumas desenvolvem atividades que despertam suspeita entre envolvidos (as) com o tráfico de drogas. No caso relatado sobre a estudante do curso de segurança, a ação violenta dos traficantes faz parte da estratégia para ostentar e manter o seu poder sobre os demais. Além do estupro e espancamento, as humilhações públicas, para que todos fiquem cientes de suas ações.

A condição de gênero é fator que define especificidades no que diz respeito às ocorrências de agressões e assassinatos. Mulheres 
são agredidas e estupradas como estratégia para a manutenção da submissão do restante dos moradores; e são assassinadas como pagamento de dívidas contraídas pelos companheiros com o tráfico. Além disso, enfrentam a partilha do patrimônio entre os traficantes da região, quando decidem deixar o bairro e venderem suas casas, sob a ameaça de morte. Marta confirma: - Outro dia foi com a mulher do policial. [...] Invadiram a casa dele e bateram nela, acabaram com ela atrás da arma do marido dela. Contudo, Thaís apresenta uma particularidade na ação dos (as) envolvidos (as) do local, afirmando que:

As mulheres [...] pagam dívidas dos filhos viciados, aos traficantes. Todos os dias, os traficantes batem na porta das mães, cobrando, só que fazem com educação, chamam e conversam [...]. As mães dos traficantes são protegidas e respeitadas por eles, até as dos rivais, ninguém mexe. [...] eles tem normas. (MP Thaís, 30/11/2012).

As mães de usuários/envolvidos são respeitadas pelos demais envolvidos porque pagam as dívidas dos filhos, mas também ocupam um lugar privilegiado quando na condição de mães de traficante. Assim, tanto umas como outras cuidam dos seus e, por isso, ambas ficam livres de agressões e assassinatos.

\section{ÚLTIMAS CONSIDERAÇÕES}

O cotidiano das Mulheres da Paz do bairro de São Cristóvão, na cidade de Salvador-BA, é atravessado pela violência constitutiva da ordem social. Reconhecida pelo Estado, a região, ao lado dos demais contextos nacionais, enfrenta o que Caldeira (2000, p. 10) designou como o “[...] universo do crime [...]", respaldado em uma série de elementos que o retroalimentam. O resultado, então é a produção de interpretações, geralmente, permeadas pelo uso de estereótipos, preconceitos e racismo, reorganizando os espaços a partir dos novos sentidos que lhes são atribuídos.

O processo de institucionalização da violência pelo Estado suscita várias discussões na sociedade e no mundo político. Ao ignorar a interface entre racismo, pobreza, arbitrariedade policial e discriminação de gênero, o Estado deixa de criar possibilidades de saída das relações de conflitos sociais destrutivos, que rompem 
os laços de sociedade (SIMMEL, 1983). Assim, nega direitos de cidadania a grupos sociais, como o de mulheres negras, pobres, residentes em espaços desprivilegiados.

As mulheres fortaleceram sua autoestima, ao abraçarem uma nova identidade, a de Mulher da Paz, num ambiente de conflitos destrutivos e, sentiram-se valorizadas por atuarem em benefício da comunidade, o vínculo entre elas se solidificou, gerando o sentimento de pertencimento ao grupo. Ao mesmo tempo, passaram a reconhecer direitos que possuíam, vislumbrando a possibilidade de saída da situação de violência doméstica, como foi o caso de algumas entre elas.

Todavia, o processo formativo não atendeu às suas expectativas de acesso aos serviços públicos, jurídicos, médico-hospitalar, socioassistenciais, psicológicos, de emprego e educacionais. Dessa forma, somente as poucas mulheres que já contavam com alguns recursos puderam galgar novas posições sociais. Finalmente, o projeto reforçou papeis tradicionais de gênero, ao se isentar do cuidado sobre a população jovem afetada pela criminalidade violenta e, atribuir às mulheres o papel de mediadoras. As Mulheres da Paz, ao serem designadas para cuidarem dos outros, mais uma vez deixaram de ser cuidadas, persistindo a condição de violência, pobreza, opressão racial e de gênero que permeia seu cotidiano.

\section{REFERÊNCIAS}

ALMEIDA, S. S. Essa violência mal-dita. In: ALMEIDA, S. S. (Org.). Violência de gênero e políticas públicas. Rio de Janeiro: UFRJ, 2007.

ALVAREZ, S. Politizando as relações de gênero e engendrando a democracia. In: STEPAN, A. (Org.). Democratizando o Brasil. Rio de Janeiro: Paz e Terra, 1988.

AVRITZER, L. A participação social no nordeste. Belo Horizonte: UFMG, 2007.

BAIRROS pobres são reféns das gangues. A Tarde, Salvador, 10 jul. 2006. Disponível em: <http://liderancadoptbahia.com.br/novo/ noticias.php?id_noticia=3114>. Acesso em: 5 jan. 2013. 
BEATO, C.; ZILLI, L. F. A estruturação das atividades criminosas: um estudo de caso. Revista Brasileira de Ciências Sociais, São Paulo, v. 27, n. 80, out. 2012.

BONETTI, A. de L. Entre femininos e masculinos: negociando relações de gênero no campo político. Cadernos Pagu, São Paulo, n. 20, p. 177-203, 2003.

BORGES, R. C. de O.; PINHEIRO, D. R. de C. A importância da liderança comunitária no processo de desenvolvimento local.

Revista GeoUECE, Fortaleza, v. 1, n. 1, dez. 2012.

BORGES, A. M. de C.; CARVALHO, I. M. M. de. Segregação urbana em Salvador e emprego: observações preliminares sobre Salvador. In: ENCONTRO NACIONAL DE ESTUDOS POPULACIONAIS. 18.; 2012. Anais..., Águas de Lindóia: ABEP, de 19 a 23 de novembro de 2012. p. 1-18.

BRASIL. Lei no.11.530, de 25 de outubro de 2007. Institui o Programa Nacional de Segurança e Cidadania - PRONASCI e dá outras providências. Brasília (DF), 2007. Disponível em: <http://legis.senado.gov.br/legislacao/ListaPublicacoes. action?id=256230 >. Acesso em: 12 jun. 2017.

BRASIL. Medida Provisória 416, de 23 de janeiro de 2008. Altera a Lei no. 11.530, de 24 de outubro de 2007 e dá outras providências. Brasília (DF), 2008. Disponível em: <http://www.planalto.gov.br/ ccivil_03/_Ato2007-2010/2008/mpv/416.htm>. Acesso em: 10 jun. 2010.

BRASIL. O que é o Pronasci. Brasília (DF), 2010. Disponível em: <http://portal.mj.gov.br/data/Pages/MJE24DoEE7ITEMIDAF1131EAD238415B96108AoB8AoE7398PTBRNN.htm.>

BRONZO, Carla. Vulnerabilidade, empoderamento e metodologias centradas na família: conexões e uma experiência para reflexão. In: CONCEPÇÃO e Gestão da Proteção Social Não-Contributiva no Brasil. Brasília (DF): Ministério do Desenvolvimento Social e Combate à Fome; Unesco, 2009. p. 171-201.

CALDEIRA, T. P. do R. Cidade de muros: crime, segregação e cidadania. Tradução Frank de Oliveira e Henrique Monteiro. São Paulo: 34; Edusp, 2000. 
CALDEIRA, T. P. do R. Mujeres, cotidianidad y política. In: JELIN, E. Participacion, ciudadania y identidad: lãs mujeres em lós movimientos sociales latino-americanos. Coimbra: UNRISD, 1987. p. 77-128.

CARNEIRO, S. Racismo, sexismo e desigualdade no Brasil. São Paulo: Selo Negro, 2011.

DELGADO, J.; TAVARES, M. S. (Trans)versalidades de Gênero e geração nas políticas sociais: o lugar de mulheres e idosos. Caderno Espaço Feminino, Uberlândia, v. 25, n. 2, p. 79-97, jul./ dez. 2012.

DETTMAR, G.; SILVEIRA, L. População carcerária feminina aumenta $42 \%$ nos últimos cinco anos. Portal CNJ, Brasília (DF), 20 ago. 2013. Disponível em: <http://www.cnj.jus.br/noticias/ cnj/60614-populacao-carceraria-feminina-aumenta-42-nos-ultimoscinco-anos>. Acesso em: 30 nov. 2013.

DOURADO, F. A população carcerária feminina aumentou $256 \%$ em 2012. Bahia Repórter, Salvador, 26 jul. 2013. Disponível em: <http://www.bahiareporter.com.br/ultimas_noticias. php?codnoticia=29780>. Acesso em: 30 nov. 2013.

FANON, F. Em defesa da revolução africana. Lisboa: Sá da Costa, 1980. (Terceiro Mundo).

FERNANDES, R. B.; REGINA, M. E. A segregação residencial em Salvador no contexto do miolo da cidade. Cadernos do Logepa, João Pessoa, v. 4, n. 1, p. 39-46, 2005.

GAMA, A. S. As contribuições e os dilemas da crítica feminista para a análise do Estado de Bem-Estar Social. Ser Social, Brasília (DF), v. 10, n. 22, p. 41-68, jan./jun. 2008.

GOMES, C.; SORJ, B. O gênero da nova cidadania: o Programa Mulheres da Paz. Sociologia \& Antropologia, Rio de Janeiro, v. 1; 2, p. 147-164, 2011.

HARAWAY, Donna. Saberes localizados: a questão da ciência para o feminismo e o privilégio da perspectiva parcial. Cadernos Pagu, São Paulo, n. 5, p. 7-41, 1995.

MACHADO, E. P.; NORONHA, C. V. A polícia dos pobres: violência 
policial em classes populares urbanas. Sociologias, Porto Alegre, ano 4, n. 7, p. 188-221, jan./jun. 2002.

MARIANO, S. A.; CARLOTO, C. M. Gênero e combate à pobreza: Programa Bolsa Família. Estudos Feministas, Florianópolis, v. 17, n. 3, p. 901-908, set./dez. 2009.

MILANI, C. R. S. Políticas públicas locais e participação na Bahia: o dilema gestão versus política. Sociologias, Porto Alegre, ano 8, n. 16, p. 180-214, jul./dez. 2006. Disponível em: <http://www.scielo.br/ pdf/soc/n16/ao8n16.pdf>. Acesso em: 3 jun. 2013.

PEREIRA, G. C. Habitação e infraestrutura urbana em Salvador e Região Metropolitana. In: CARVALHO, I.M.M.; PEREIRA, G. C. Como anda Salvador e sua região metropolitana. 2. ed. rev. Salvador: EDUFBA, 2008.

PEREIRA, P. A. Mudanças Estruturais, política social e papel da família: crítica ao pluralismo de bem-estar. Cap. I. In: SALES, M. A.; DE MATOS, M. C.; LEAL, M. C. (orgs.). Política Social, família e Juventude. 6. ed. São Pulo: Cortez, 2010.

ROCHA, F. dos S. "Botou foi a gente no fogo! Queria ver a gente se queimar!": um estudo sobre as Mulheres da Paz de São Cristóvão, Salvador -BA. 241 f., 2013. Dissertação (Mestrado)Universidade Federal da Bahia, Faculdade de Filosofia e Ciências Humanas, 2013.

SANTOS, E. et al. (Orgs.). O caminho das águas em Salvador: bacias hidrográficas, bairros e fontes. Salvador: CIAGS/UFBA; SEMA, 2010. (Coleção Gestão Social).

SARDENBERG, C. Liberal vs liberating empowerment: conceptualizing empowerment in Latin American feminist perspective. In: SEMINÁRIO “PATHWAYS OF WOMEN'S EMPOWERMENT”. Anais... Luxor: IDS; American University in Cairo, set. 2006.

SARDENBERG, C. A mulher frente à cultura da eterna juventude. In: FERREIRA, S. L.; NASCIMENTO; E. R. do. (Orgs.): Imagens da mulher na cultura contemporânea. Salvador: NEIM/UFBA, 2002, p. 51-68. (Coleção Bahianas, v. 7).

SCHUTTE, G. R.; JOSÉ, M. K. Aliança de cidades, a vez dos 
Alagados: a construção de um programa integrado de urbanização de favelas em Salvador. São Paulo: Aliança de Cidades, 2008.

SILVA, L. A. M. da. (Org.) Vida sob cerco: violência e rotina nas favelas do Rio de Janeiro. Rio de Janeiro: Nova Fronteira, 2008.

SIMMEL, G., A natureza sociológica do conflito. In: MORAES FILHO, Evaristo (Org.). Simmel. São Paulo: Ática, 1983. Disponível em: <http://www.iseg.utl.pt/aula/cad95/A\%20Natureza\%20 sociologica\%20do\%20conflito.pdf>. Acesso em: 4 jun. 2014. SOUZA, K. O. J. de. A pouca visibilidade da mulher brasileira no tráfico de drogas. Psicologia em Estudo, Maringá, v. 14, n. 4, p. 649-657, out./dez. 2009.

TRONTO, J. Mulheres e cuidados: o que as feministas podem aprender sobre a moralidade a partir disso? In: JAGGAR, A.; BORDO, S. (Orgs). Gênero, corpo e conhecimento. Rio de Janeiro: Record; Rosa dos Tempos, 1997. p. 186-203.

ZALUAR, A. A Máquina e a revolta: as organizações populares e o significado da pobreza. 2. ed. São Paulo: Brasiliense, 1985. 